\title{
O LAZER E A ESCOLA PÚBLICA DE ENSINO MÉDIO EM ERMELINO MATARAZZO
}

\author{
Recebido em: 28/11/2010 \\ Aceito em: 31/05/2011
}

Madalena Pedroso Aulicino

Escola de Artes, Ciências e Humanidades da USP

São Paulo - SP - Brasil

\begin{abstract}
RESUMO: O objetivo deste trabalho foi contribuir para a análise da relação entre o uso de escolas públicas como espaços de lazer em periferias de baixa renda do Município de São Paulo. A partir de breve resgate teórico, sobre lazer, desigualdade social, dependência e educação no Brasil, relatou-se pesquisa feita no ano de 2009, entre moradores de Ermelino Matarazzo, que procurou avaliar a contribuição para o sentimento de pertencimento, de identidade, a partir do uso de escolas públicas aos finais de semana para práticas de lazer, o que foi confirmado pelos resultados. Além disso, parcela significativa dos entrevistados estaria disposta a colaborar voluntariamente para a manutenção/ampliação dessas atividades e identificou-se também que se sentir "dono" da escola implicaria em poder decidir algo a respeito dela. Aponta-se assim também, dentro dos limites da pesquisa, a necessidade de uso de políticas públicas mais participativas o que nenhuma condição sócio econômica pode impedir de acontecer.
\end{abstract}

PALAVRAS-CHAVE: Atividades de Lazer. Áreas de pobreza. Políticas Publicas.

\section{PUBLIC HIGH SCHOOL AND LEISURE IN ERMELINO MATARAZZO}

ABSTRACT: The aim of this study was to analyze the relationship between the use of public schools as places of recreation in low-income suburbs of São Paulo. After a brief review of the literature on leisure, social inequality, underdevelopment and education in Brazil, it was reported the survey in 2009 among residents of Ermelino Matarazzo. This survey assessed the contribution to the sense of belonging, identity, use of public schools during the weekend for recreation, which was confirmed by the results. In addition, a significant portion of respondents would be willing to volunteer for the maintenance or expansion of these activities and was also identified that they feel "ownership" and that this feeling would have the power to choose the future or future activities on the school. It is also reported the need to use more participatory public policy, something that no socio-economic status cannot avoid from happening.

KEYWORDS: Leisure Activities.Poverty areas. Public Policies. 


\section{Introdução}

O principal objetivo desta pesquisa foi analisar possibilidades de uso do espaço de escolas públicas de ensino médio, como espaços de lazer, principalmente em áreas de periferia de baixa renda no Município de São Paulo e em especial na região de Ermelino Matarazzo, onde foi instalada a Escola de Artes, Ciências e Humanidades -EACH, da Universidade de São Paulo.

A partir de abordagem sobre desigualdade social e lazer no espaço urbano brasileiro, com destaque para a Metrópole de São Paulo, apresentou-se uma breve contextualização da questão do lazer no Brasil, além de várias perspectivas por meio das quais ele (lazer) é analisado. Chegou-se então a um resumido relato de fases da educação brasileira até o momento atual, e já em relação ao Estado de São Paulo, com o uso da escola pública para práticas de lazer. A seguir foi feita a apresentação da pesquisa que procurou cruzar essas duas variáveis: lazer e escola pública, buscando analisar principalmente, a relação entre práticas de lazer aos finais de semana nas escolas de ensino médio e a identificação com essas mesmas escolas.

Foram aplicados noventa questionários na região de Ermelino Matarazzo para pessoas de ambos os sexos, maiores de dezoito anos e mais dez questionários entre voluntários e educadores envolvidos com as atividades do Programa Escola da Família, Os resultados confirmam, entre outras coisas, que é maior possibilidade de identificação com a escola na qual se pratica atividades de lazer, o que reforçaria a sensação de pertencimento comunitário. Além disso, quarenta e dois por cento dos entrevistados estaria disposta a colaborar voluntariamente para a manutenção e ampliação dessas atividades.

Um outro dado interessante, é que parte dos entrevistados não se sente "dono" das 
escolas públicas do Bairro, porque não têm nenhum poder de decisão sobre elas, embora tenham consciência, por vezes, de que as escolas constituem-se em bens públicos que resultam da contribuição dos impostos pagos por eles mesmos.

\section{Espaço urbano, desigualdade social e lazer no Brasil}

A redução das desigualdades sociais constitui-se num dos principais desafios enfrentados pelo Brasil no momento, desigualdade que se projeta na organização do espaço geográfico e se traduz por especializações espaciais.

No caso do espaço urbano, uma das variáveis mais importantes é aquela relativa ao tamanho da cidade, que define a relação centro x periferia, segundo Andrade (1998). Assim, nas pequenas e médias cidades, o centro urbano ainda é valorizado como espaço de comércio e de moradia, enquanto na periferia se instala a população de baixa renda; nas cidades grandes, a relação se inverte e o centro perde valor como moradia, transformando-se em área de serviços, enquanto a periferia melhor localizada, marcada pela salubridade e de mais beleza paisagística, valoriza-se como espaço de moradia da população de alta renda, restando então à população de baixa renda, as áreas periféricas que não se enquadram nessas características.

E o lazer se constitui nesse contexto, em mais uma dimensão de desigualdade social, na medida em que submetido à condição quase exclusiva de mercadoria, impõe restrições óbvias às mesmas populações de baixa renda das periferias menos valorizadas.

Além disso, segundo Marcellino (2004), ao se analisar a democratização cultural no espaço urbano, constata-se características indesejáveis, quais sejam: a centralização de equipamentos específicos como teatros, cinemas, centros culturais etc. A localização desses mesmos equipamentos em espaços para públicos segmentados; o ar de "santuário" que reveste bom número deles e as dificuldades de uso de equipamentos não específicos como as próprias residências, bares e escolas. Ou seja, a escola é apresentada aqui como um equipamento não 
específico de lazer, com grandes possibilidades em função do espaço disponível nos vários campos de interesse, como quadras, pátios, auditórios, salas etc.

Sem contar ainda com os períodos de ociosidade, seja nas férias ou nos finais de semana e principalmente os vínculos com a comunidade próxima; usualmente, as escolas só são abertas para festas com vistas à arrecadação de fundos para sua manutenção, porque paira sempre o medo de uma possível depredação. Entretanto, Marcellino (2004) comenta que se bem realizada, o uso regular da escola para o lazer, só aumenta o respeito das pessoas que passam a colaborar para sua preservação.

A partir dessas primeiras colocações é que se pensou em desenvolver uma pesquisa no Bairro e Distrito Municipal de Ermelino Matarazzo, uma periferia carente, na qual se abriga uma população de baixa renda, em que a instalação da EACH representa uma importante ação de reversão desse cenário, seja pelo potencial de valorização da comunidade local e do espaço que a abriga, seja pela ampliação e diversificação de serviços oferecidos, sem contar o resgate da auto-estima e do próprio processo de democratização da produção do conhecimento.

Embora sejam muitas as carências a que as periferias de baixa renda estejam sujeitas, afortunadamente, a escola pública não é uma delas e está lá, presente: bem ou mal instalada, com maior ou menor qualidade e maior ou menor assiduidade do corpo docente; mas talvez como o único ou mais importante equipamento público que se faz necessariamente presente nesse tipo de periferia. Por outro lado, entre as tantas carências dessa mesma periferia, o lazer é uma delas e talvez uma das que revelam mais significativamente, a condição de exclusão a que estão submetidos seus moradores.

Não deixa de ser preocupante essa situação, na medida em que para alguns pesquisadores, como Dumazedier (2004), por exemplo, o lazer é na atualidade, um instrumento de inserção e de distinção social. Isso significa que além das precárias e dificultosas condições de vida das populações das periferias de baixa renda, distantes das áreas 
privilegiadas de serviços de boa qualidade, por vezes sem saneamento básico, sem sistema de transporte eficiente, em bairros que não atendem em um mínimo os padrões de urbanismo, elas também estão mais uma vez excluídas por não terem acesso a equipamentos públicos de lazer e eventos afins.

Para muitos, isso se constituiria num fator motivador de violência, principalmente para a população jovem que cursa o ensino médio, e que por carências sociais e econômicas `as quais está submetida, fica desprovida do enriquecimento cultural e desenvolvimento que o lazer poderia proporcionar.

Nesse contexto, o poder público, tanto na esfera municipal como na estadual, procurou atenuar essa carência de espaço-tempo de lazer, criando, entre outros objetivos, os Centros de Educação Unificada - CEU's, no Município de São Paulo, e a Escola da Família, para as escolas de ensino fundamental e médio, submetidas, nos vários municípios de São Paulo, ao governo do Estado; ambas as iniciativas foram criadas em administrações passadas, mas ainda se mantém nas atuais, embora com alguns ajustes.

No presente estudo, a pesquisa concentrou-se no caso das escolas estaduais de ensino médio, que implantaram e ainda mantém atividades recreativas aos finais de semana, com destaque para o programa Escola da Família.

E foi nesse cenário que se desenvolveu a pesquisa sobre o lazer e a escola pública, buscando-se contribuir no sentido de se detectar quais as demandas das populações locais a respeito de lazer, como essas ações são avaliadas pelos envolvidos e usuários em geral, e se há uma relação de identificação com a escola, a partir de seu uso como espaço de lazer.

Isso, apesar das restrições com que essas ações são por vezes avaliadas, na medida em que teriam como objetivo principal, do ponto de vista oficial, a redução dos níveis de violência nessas mesmas periferias de baixa renda, aplicando-se assim medidas paliativas para carências mais estruturais. 


\section{Lazer: contextualização histórica}

A questão do lazer assumiu significado expressivo nesse tempo urbano-industrial ou pós-moderno e pode ser entendido, segundo Dumazedier (2004, p.34), como:

[...] um conjunto de ocupações às quais o indivíduo pode entregar-se de livre vontade, seja para repousar, seja para divertir-se, recrear-se e entreter-se ou, ainda para desenvolver sua informação ou formação desinteressada sua participação social voluntária ou sua livre capacidade criadora após livrar-se ou desembaraçar-se das obrigações profissionais, familiares e sociais.

Ainda para o mesmo autor, embora a reflexão sobre o tempo fora do trabalho tenha antecedentes longínquos, foi principalmente a partir do nascimento da sociedade industrial que se previu a importância do tempo liberado pela redução do trabalho industrial, e na verdade, a Revolução Industrial implicou em dois tipos de transformação, que acabaram resultando na configuração e fortalecimento do papel do lazer.

A primeira, porque embora a atividade de lazer seja intrínseca ao próprio homem e por extensão, a todos os grupos sociais, passou a ter uma dimensão mais significativa a partir da passagem da sociedade agrária x feudal para a sociedade urbano-industrial; na primeira, segundo Camargo (1992), o ritmo de trabalho era longo e cansativo, mas respeitava os ciclos de parada e descanso pautados pelas condições naturais como, o dia e a noite e as estações do ano; já na sociedade urbano-industrial, os horários de trabalho passam a ser rígidos e extensos, com pouquíssimas e curtas paradas, praticamente sem férias; além disso, na produção industrial praticamente rompe-se à relação entre o tempo e o produto do trabalho, que se torna fragmentado e de difícil compreensão, principalmente por sua complexidade tecnológica.

Nesse contexto, era natural a luta pela redução da jornada diária e anual de trabalho, liberando-se assim tempo para o lazer, que passou a acumular então a dimensão de realização e de compensação pelo trabalho repetitivo e aparentemente sem sentido, ao qual agora a maioria dos trabalhadores parecia estar sujeita. Constitui-se então a segunda transformação que se 
traduz na busca de mais tempo para atividades livres e prazerosas, distantes das obrigações que se opõem ao lazer, e que segundo Dumazedier (2004) dizem respeito ao trabalho profissional, o trabalho suplementar, os trabalhos domésticos, as atividades de manutenção pessoal como as refeições, cuidados higiênicos e o sono, as atividades rituais ligadas às obrigações familiares, sociais e espirituais e aquelas atividades ligadas aos estudos interessados para exame escolar ou profissional.

Ainda a partir do mesmo autor e como já expresso em definição apresentada anteriormente, à atividade de lazer estão associadas três funções básicas: a de descanso, liberando-se da fadiga; a função de divertimento, recreação e entretenimento que funciona como espécie de compensação ou mesmo de fuga às obrigações intrínsecas ao funcionamento da sociedade urbano-industrial e por último, a função de desenvolvimento, que entre outros elementos, está associada ao processo de aprendizagem voluntária, com vistas ao desenvolvimento pessoal e social da personalidade.

Essa mesma Revolução Industrial, já referida anteriormente, que teve início na Europa, Inglaterra e França, mais precisamente, a partir do século XVIII, estendeu-se por muitos outros países entre os séculos XIX e XX, e após a segunda grande Guerra Mundial, colaborou para configurar a divisão dos vários países em capitalistas desenvolvidos e subdesenvolvidos (excluindo-se então os socialistas), exatamente a partir, do grau de desenvolvimento industrial, além também da potencialidade econômica, representada entre outros fatores, por um mercado interno com capacidade de consumo (ANDRADE, 1998).

A partir daí, constitui-se a grande empresa, inicialmente industrial, e em seguida também no setor de serviços, mas que de uma forma ou de outra, difundiu-se pelo planeta, ultrapassando as fronteiras dos vários países e se configurando no que se convencionou chamar de corporação multinacional ou transnacional, mais precisamente. 
O cenário atual é de fortalecimento exatamente dessas grandes corporações, que passaram a atuar pela desregulamentação dos mercados, embora usualmente numa via de mão única, ou seja, principalmente de países agora em vias de desenvolvimento para os efetivamente desenvolvidos. Esse é um dos aspectos que caracteriza o chamado fenômeno da globalização, que resultou também do avanço tecnológico que no sistema de transporte e de comunicação, encurtou as distâncias e praticamente faz a informação e a notícia ser acessada em tempo real, praticamente em todos os cantos do globo, transformando o mundo nessa aparente grande aldeia que acabou por uniformizar condutas e modos de ser, agir, sentir e imaginar (IANNI, 2001).

Por outro lado, paradoxalmente, a reação a essas tendências faz-se sentir em nível de países, no processo de regionalização de mercados, como a União Européia, por exemplo, e em nível individual, de personalização, segundo Haesbaert (1999), ou seja, de afirmação do indivíduo e mesmo de valorização de práticas culturais locais, por exemplo.

E é nesse cenário de um mundo globalizado tão complexo e homogeneizado, que o lazer acaba por se configurar como uma forma de diferenciação e de inserção social, ao qual muitos não tem acesso, intensificando a consciência e a condição de exclusão, em especial na periferia menos favorecida, como aquela em que está localizada a Escola de Artes, Ciências e Humanidades - EACH; e é exatamente nesse ambiente que se pretende pesquisar as possibilidades de lazer via escola pública, exatamente para se tentar apontar caminhos que possam contrapor-se a essa carência.

\subsection{O lazer no Brasil}

Pensar a questão do lazer no Brasil implica em se remeter `a política assistencialista do bem estar social, nos anos 30 e 40, segundo Pinto (2008), na medida em que as 
Constituições de 1934, de 37 e a Consolidação das Leis do Trabalho de 1943 fazem referência ao descanso semanal, férias remuneradas e jornada de oito horas diárias.

Ainda segundo a mesma autora, data dessa mesma época a inclusão na Declaração Universal dos Direitos do Homem, da Organização das Nações Unidas, - ONU, da qual o Brasil é signatário, do direito que todo ser humano tem ao lazer, mas tratado como um tempo diferente do tempo de repouso, o que se pode constatar ainda hoje, no artigo 24 dessa mesma Declaração ${ }^{1}$,

É preciso citar ainda, nessa mesma linha, a criação do Serviço Social da Indústria SESI e do Serviço Social do Comércio - SESC, apresentados inicialmente como soluções para prestação de serviços de educação, saúde, lazer e ação social dos trabalhadores da indústria, do comércio e de suas famílias.

Em 1964, o Estatuto da Terra e do Trabalhador Rural estendia aos trabalhadores rurais os mesmos direitos dos trabalhadores urbanos, como férias, aposentadoria etc. e a tônica de todas essas estratégias era incluir o lazer dentro de uma política assistencialista, a partir de uma recreação orientada, supondo a existência de um doador e de um receptor (PINTO; MARCELLINO, 2008).

Na década de 60 surgem as Ruas de Recreio, mais tarde chamadas de Ruas de Lazer, que se difundiram de forma a se constituírem no "modelo de política pública brasileira de lazer da maioria dos municípios e estados brasileiros...", com a realização de eventos esporádicos e discriminatórios. (PINTO; MARCELLINO, 2008, p.84). Data dessa época também, segundo a mesma autora, a consagração da área da educação física como principal agente difusor das políticas de lazer no Brasil.

Os princípios orientadores dessas políticas eram e por vezes continuam sendo funcionalistas, a partir de várias abordagens, conforme Marcellino (2008) que destaca para o

\footnotetext{
1 http://www.fd.uc.pt/igc/enciclopedia/onu/textos onu/dudh.pdf . Acesso em: 03 jun. 2009.
} 
lazer, a perspectiva: romântica (de volta a um passado ingênuo e feliz); moralista (no sentido de sua importância para a manutenção da ordem e segurança social); compensatória (como oposição ao trabalho alienado e fragmentado da sociedade atual) e a utilitarista (para recuperação da força de trabalho).

Na década de 80 o processo de redemocratização do País aumenta a participação de atores sociais na sociedade brasileira em geral, e a par de outras influências, o lazer passa a ser reconhecido como força econômica e necessário à melhoria da qualidade de vida das pessoas em geral e não só para os trabalhadores; na década de 90, a partir do modelo neoliberal adotado, registra-se uma tendência de liberar o Estado de obrigações públicas de proteção social, compartilhando-se as responsabilidades de lazer com outras políticas sociais e inclusivas, como o Estatuto da Criança e do Adolescente (1990), do Idoso (2003) e da Política Nacional para a Integração das Pessoas Portadoras de Deficiência (PINTO, MARCELLINO, 2008).

Na verdade, o lazer é um espaço-tempo que continua a ser temido pela sociedade, na medida em que, segundo Dumazedier (2004, p.270), o "tempo livre é o tempo preferido para todas as formas de decadência e de florescimento humano".

Daí se pode entender as várias tendências acima expostas, sobre a abordagem do lazer, numa perspectiva romântica, moralista, compensatória ou utilitarista.

De uma forma ou de outra, o lazer assumiu vários significados na atual sociedade, como indicador de distinção social e de erudição e simultaneamente, como uma mercadoria que o mercado explora em todos os sentidos, inclusive por sua mais recente associação com a questão da qualidade de vida. 


\section{Educação, subdesenvolvimento e dependência: a acumulação entravada}

Numa breve retrospectiva histórica e segundo Freitag (1979), é preciso refletir sobre a política educacional brasileira a partir do contexto mais amplo da sociedade brasileira, na qual ela se insere e da qual é fruto e a característica mais marcante constitui-se na perspectiva da dependência, que configurou momentos históricos de forma bem específica.

E não há como negar esse fato; entretanto, a par de todas as teorias escritas sobre subdesenvolvimento e dependência, é importante destacar as reflexões de Deak (1999) que procura romper parâmetros dessas duas teorias, destacando o caráter autônomo do processo de reprodução social no Brasil, porque ambas acabam por obstruir a análise e gerar uma espécie de imobilização política. A primeira porque coloca o desenvolvimento como um estágio ou caminho a ser atingido quase naturalmente, e a segunda, porque situa a questão em nível das relações internacionais, expressas entre outras coisas pelo imperialismo e pelas trocas desiguais. Ambas as teorias foram bem aceitas e incorporadas pela ideologia dominante, porque situam o âmago dos problemas fora da sociedade brasileira, compatibilizando-se com o status quo vigente de fato, o que na prática as tornava inócuas.

Em função disso, Deák (1999) propõe a teoria da acumulação entravada, que se diferencia da exploração colonial e da acumulação capitalista e tem o Estado como base institucional de sua reprodução; em nível das relações sociais, a sociedade brasileira se configura como de elite, diferenciando-se da burguesa, porque não predomina o princípio de generalização da forma mercadoria. O Estado acaba por atuar de forma antagônica, privilegiando a expatriação do excedente em detrimento da acumulação no mercado interno, embora se resguarde certa acumulação que vai permitir a expansão do excedente, então expatriado.

Como a produção é baseada no trabalho assalariado, a massa salarial deve acompanhar a taxa de crescimento da força de trabalho, o que resulta numa certa expansão do mercado 
interno, induzindo-se ao pleno desenvolvimento das forças produtivas e ao fortalecimento da burguesia que acaba por desafiar a dominação da elite contra a expatriação do excedente. Até a virada do século XX sucedem-se ciclos de substituições de importações, quando indústrias dinâmicas são entregues ao capital estrangeiro ou estatizadas, neutralizando-se assim o fortalecimento de forças internas que pudessem desafiar a posição da elite.

Por outro lado, ainda segundo Deák (1999), as aglomerações urbanas constituem-se no principal espaço de reprodução social, em que a acumulação extensiva gera miséria urbana, e pelo esgotamento desse estágio, a acumulação intensiva acaba impondo a instalação de uma infra-estrutura de produção de mercadorias necessárias à reprodução da força de trabalho, o que inclui transporte, telefonia/comunicação, saneamento básico, transporte e educação. Assim, a interpretação dialética do processo social brasileiro permite romper a barreira ideológica das teorias do subdesenvolvimento e da dependência, interpretando a atual crise pelo que ela é e rompendo com a visão de que o processo de desenvolvimento é determinado externamente.

\subsection{Aspectos marcantes da política educacional brasileira: breve retrospectiva}

Durante o período colonial e até 1930, segundo Freitag (1979), a economia estava organizada para a produção de produtos primários para exportação, a política educacional era praticamente inexistente, e o sistema educacional montado pelos jesuítas cumpria uma série de funções, igualmente importantes para a Coroa portuguesa, com a reprodução das condições de dominação e da ideologia dominante.

Entre 1930 e 1945, em função da crise que se generalizou e atingiu também o Brasil, a classe então hegemônica dos latifundiários cafeeiros foi forçada a dividir o poder com a nova classe burguesa emergente (FREITAG, 1979) e a política educacional assume um caráter 
universal, voltada para o trabalho produtivo, baseada no modelo norte americano (GADOTTI, 2006).

Essas tendências são mantidas até 1964, com o fortalecimento da economia de substituição de exportações diante da II Guerra Mundial e com os avanços do capital estrangeiro: rompe-se o modelo populista, que se caracteriza por uma aliança de várias classes, e tem início uma fase de degradação do ensino público e a educação se transforma numa mercadoria, largamente explorada até hoje, pelo mercado (GADOTTI, 2006).

\section{A pesquisa: hipóteses, resultados e análise}

A partir das tendências aqui delineadas, e principalmente pelas variáveis de lazer, urbanização desigualdade social, periferia de baixa renda, escola pública e identidade , é que se pensou em desenvolver a presente pesquisa, que tem como principais hipóteses:

1. Moradores e alunos de Ermelino Matarazzo avaliam positivamente as atividades de lazer que têm lugar nas escolas públicas de ensino médio do Bairro (aqui como sinônimo de distrito municipal).

2. Há moradores de Ermelino Matarazzo dispostos a atuar voluntariamente para manter e ampliar atividades de lazer nas escolas públicas do Bairro.

3. Moradores e alunos não se sentem responsáveis pelas escolas públicas, porque elas não lhes pertencem.

4. Há relação significativa entre a prática de lazer nas escolas públicas e um sentido de identificação com as mesmas escolas.

A partir daí, montou-se um questionário que foi aplicado entre população maior de 18 anos, homem ou mulher, morador ou não do Bairro e estudando ou não.

O questionário foi aplicado em noventa pessoas, além de outros dez entrevistados, na condição de educadores do Programa Escola da Família. 
Os resultados são apresentados a seguir, iniciando-se com alguns dados do Distrito Municipal de Ermelino Matarazzo.

$\begin{array}{llllll}\text { Segundo a } & \text { Prefeitura } & \text { Municipal de } & \text { São }\end{array}$ http://atlasambiental.prefeitura.sp.gov.br. Acesso em: 04 jun. 2009, a população do Distrito Municipal de Ermelino apresenta uma renda familiar de R\$1.058,00; tem em média, 6,3 anos de estudo, faixa etária de 24 anos e 4,76 \% de população favelada.

Com relação às áreas verdes, Ermelino tem uma localização privilegiada em relação a outros bairros da Zona Leste, pois toda sua extensão norte faz fronteira com o Parque Ecológico do Tietê. Devido a isso o Distrito tem $13 \mathrm{~m} 2$ de cobertura vegetal por habitante. No entanto, esta área verde não é distribuída uniformemente e todo o resto do Distrito é carente de áreas verdes; quanto ao uso do solo, a região possui alguns galpões industriais, mas a grande parte é ocupada por unidades residenciais de baixo padrão.

Os dados coletados na pesquisa foram tabulados e transformados por vezes, em gráficos que permitem uma melhor visualização e facilitam a análise e verificação dos resultados.

Quanto ao local de residência, mais de $80 \%$ dos entrevistados morava na região de Ermelino e mais de $70 \%$ por cento, morava no Bairro há mais de cinco anos; além disso, foram entrevistados 50 homens e 40 mulheres, sempre maiores de 18 anos.

No caso da ocupação, os maiores resultados agruparam-se nas posições de estudantes, assalariados e autônomos, registrando-se a presença de um profissional liberal, um empresário, três donas de casa e cinco desempregados. 


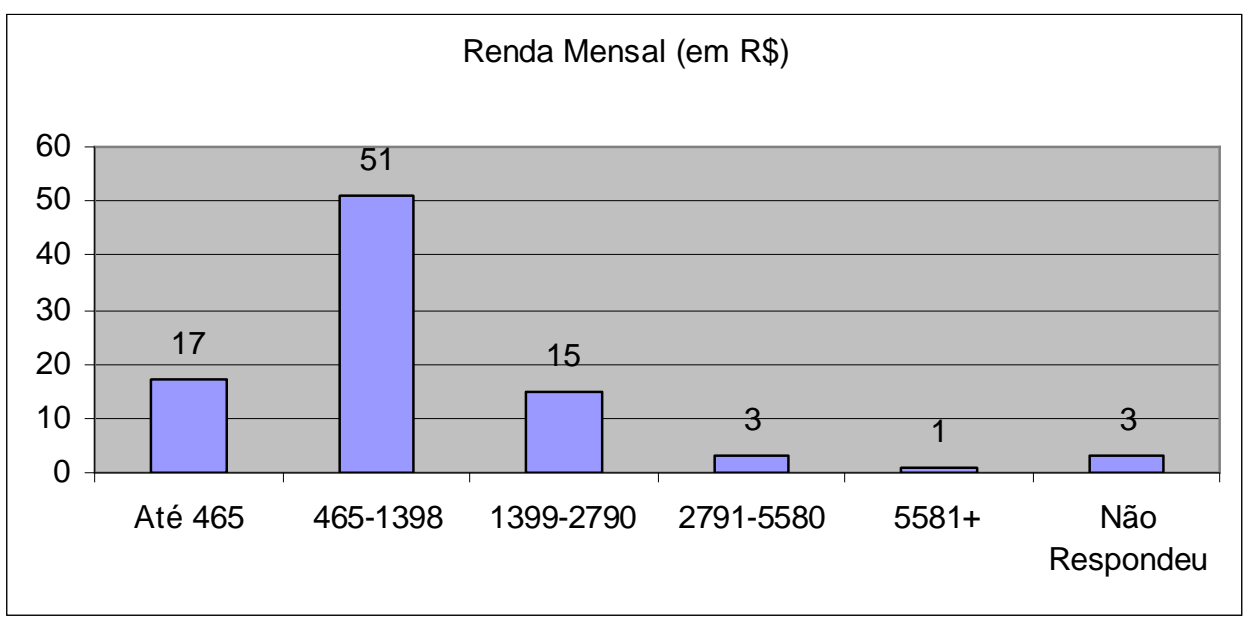

GRÁFICO 1 - Renda mensal (em R\$)

No caso da renda mensal, a maior frequência foi para a faixa entre $\mathrm{R} \$ 465,00 \mathrm{e}$ $\mathrm{R} \$ 1.398,00$, com cinquenta e um entrevistados; até $\mathrm{R} \$ 465,00$ teve-se dezessete entrevistados. Entre $\mathrm{R} \$ 1.399,00$ e $\mathrm{R} \$ 2.790,00$ é o que recebem quinze dos noventa entrevistados; além disso, um não respondeu, um recebe mais de $R \$ 5.581,00$ e três recebem entre $R \$ 2.791,00$ e $\mathrm{R} \$ 5.580,00$.

E o que se pode constatar desses dados é que a faixa de renda de Ermelino Matarazzo não é das mais baixas, informação confirmada por dados da própria Prefeitura, que aponta uma renda média de $\mathrm{R} \$ 1.058,00$, segundo a Secretaria de Planejamento http://atlasambiental.prefeitura.sp.gov.br. Acesso em: 04 maio 2009; ou seja, não é uma área de extrema pobreza. 


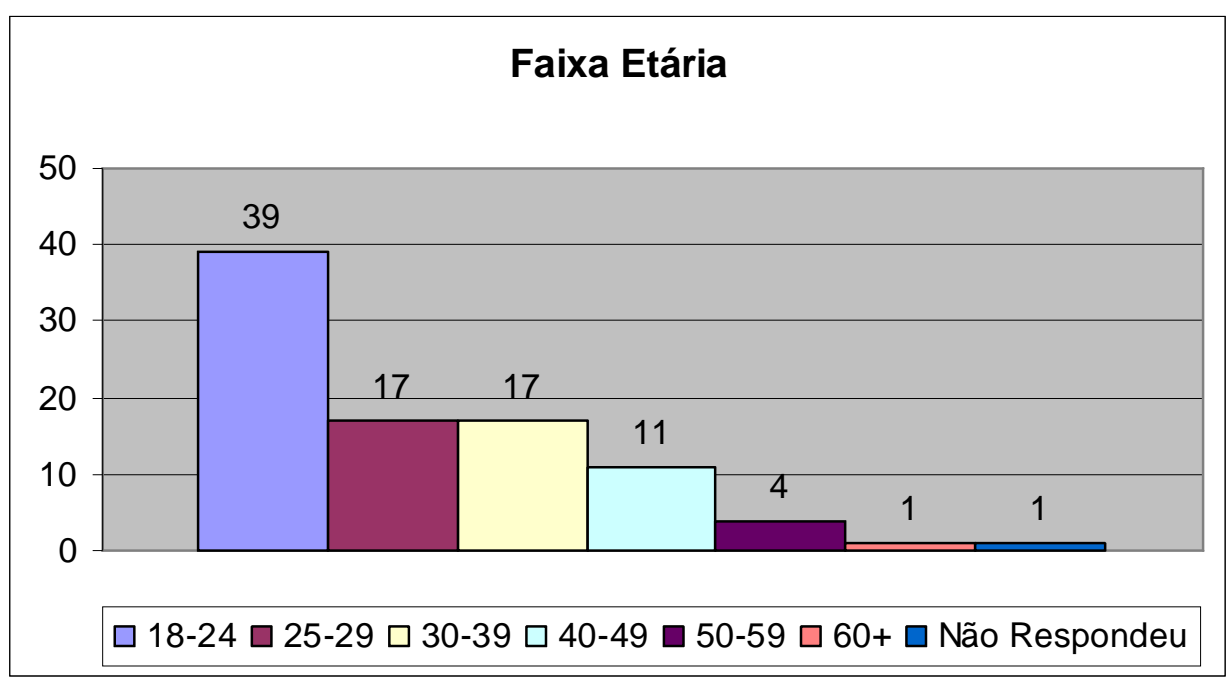

GRÁFICO 2 - Faixa etária

Foi estabelecido no início da pesquisa, que os entrevistados deveriam ter no mínimo dezoito anos, razão pela qual esse número se constitui no limite da primeira classe, entre dezoito e vinte e quatro anos, e que correspondeu a trinta e nove entrevistados, sendo a classe mais frequente. Entre vinte e cinco e vinte e nove anos, foram entrevistadas dezessete pessoas; entre trinta e trinta e nove anos, entrevistou-se também dezessete pessoas. Já entre quarenta e quarenta e nove anos, foram onze entrevistados e entre cinquenta e cinquenta e nove anos, quatro entrevistados. Um só com mais de sessenta anos e um não respondeu.

O que se pode constatar aqui também, é que há um predomínio da população jovem, o que é confirmado igualmente por dados da Prefeitura Municipal de São Paulo, via Secretaria de Planejamento, que estabelece a idade mediana da população em vinte e quatro anos. http://atlasambiental.prefeitura.sp.gov.br. Acesso em: 04 jun.0 2009. 


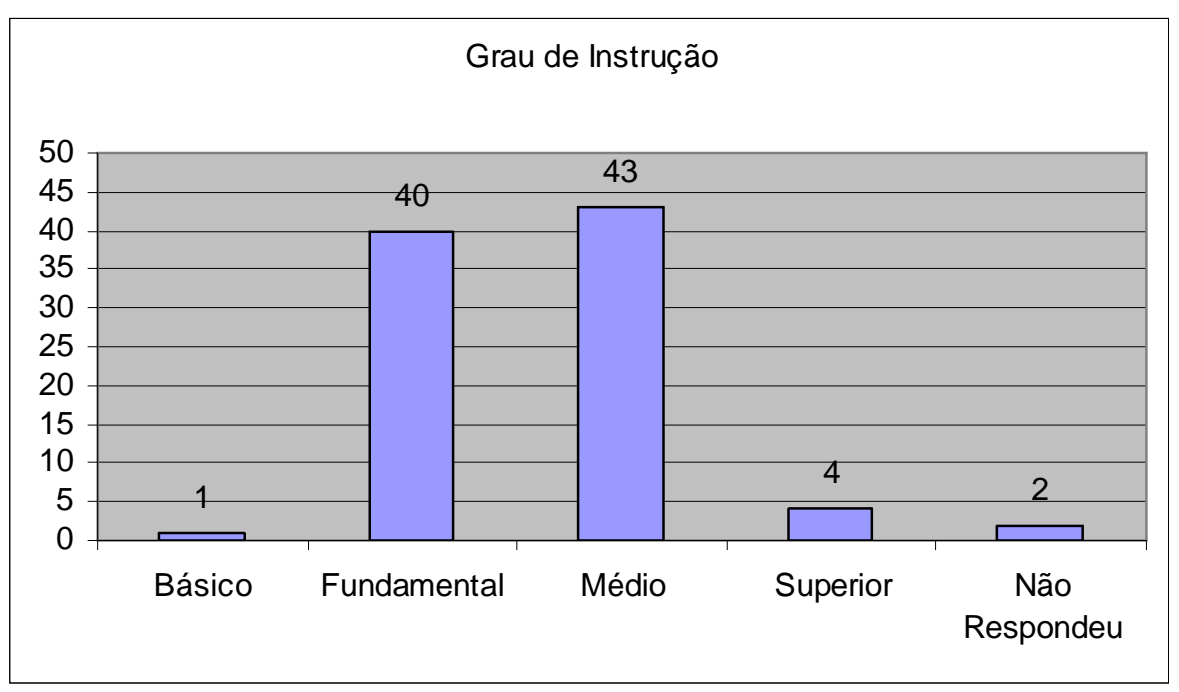

GRÁFICO 3 - Grau de instrução

No caso do grau de instrução, houve predomínio do ensino médio completo, somandose nessa categoria, quarenta e três entrevistados; no caso do ensino fundamental completo, até a oitava série, somaram-se quarenta entrevistados, com ensino básico (fundamental até a quarta série, em função da seriação atual), somente um entrevistado. Com superior completo foram quatro entrevistados e dois não responderam. Mais uma vez, o que se pode constatar é que em nível de escolaridade Ermelino Matarazzo não registra taxas elevadas de analfabetismo ou alfabetização funcional, coincidindo os resultados da pesquisa com dados da Prefeitura Municipal, que aponta o número de seis pontos de três anos de estudo, como média. http://atlasambiental.prefeitura.sp.gov.br. Acesso em: 04 jun. 2009.

Sobre a possibilidade de práticas de lazer em Ermelino, a maioria dos entrevistados, mais precisamente sessenta e quatro pessoas, respondeu negativamente, ou seja que isso não acontece no Bairro, enquanto que para vinte e cinco entrevistados, o Bairro oferece sim opções de lazer, enquanto um não respondeu. O que se pode concluir é que efetivamente o Bairro de Ermelino não oferece muitas possibilidades de lazer, a partir da presença de equipamentos específicos, inclusive como já foi comentado anteriormente; destaca-se o Parque Ecológico do Tietê como único equipamento público específico para essa finalidade, porque as praças são 
poucas e praticamente sem equipamento algum, restando somente à opção das escolas, sejam os Centros Educacionais Unificados, mantidos pela Prefeitura do Município de São Paulo, seja pelas escolas vinculadas ao Programa Escola da Família.

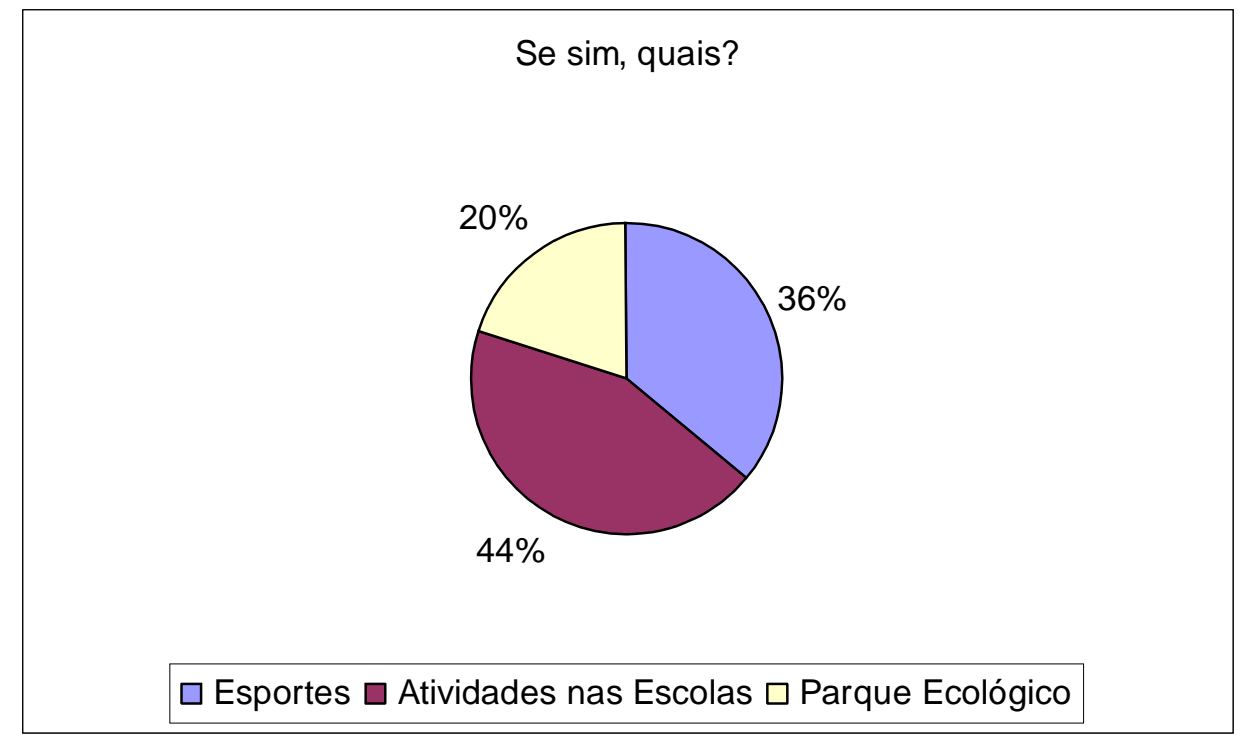

GRÁFICO 4 - Quais atividades são oferecidas?

Entre os vinte e cinco entrevistados que afirmaram existir opções de lazer no Bairro, onze citaram as atividades nas escolas, nove se referiram aos esportes e cinco ao Parque Ecológico.

Quanto ao oferecimento de lazer nas escolas, para quarenta e nove por cento dos entrevistados, as escolas não oferecem possibilidades de prática de lazer; já para quarenta e três por cento, elas (escolas) oferecem sim práticas de lazer, enquanto oito por cento não respondeu.

Foi averiguado então, se os entrevistados participavam de atividades de lazer na escola e constatou-se que entre os trinta e nove entrevistados que responderam afirmativamente à prática de lazer nas escolas, vinte e três (59\%) afirmaram já ter participado delas, enquanto dezesseis deles nunca participaram (41\%). 


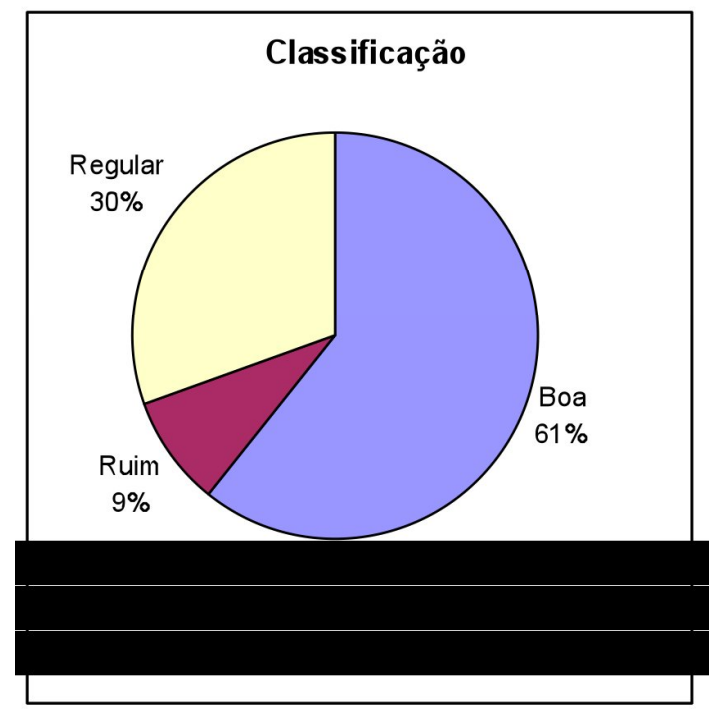

GRÁFICO 5 - Avaliação das atividades de lazer nas escolas

Entre os vinte e três entrevistados que afirmaram participar das atividades de lazer oferecidas nas escolas, sessenta e um por cento fazem uma boa avaliação, enquanto para trinta por cento elas são regulares e para nove por cento, são ruins.

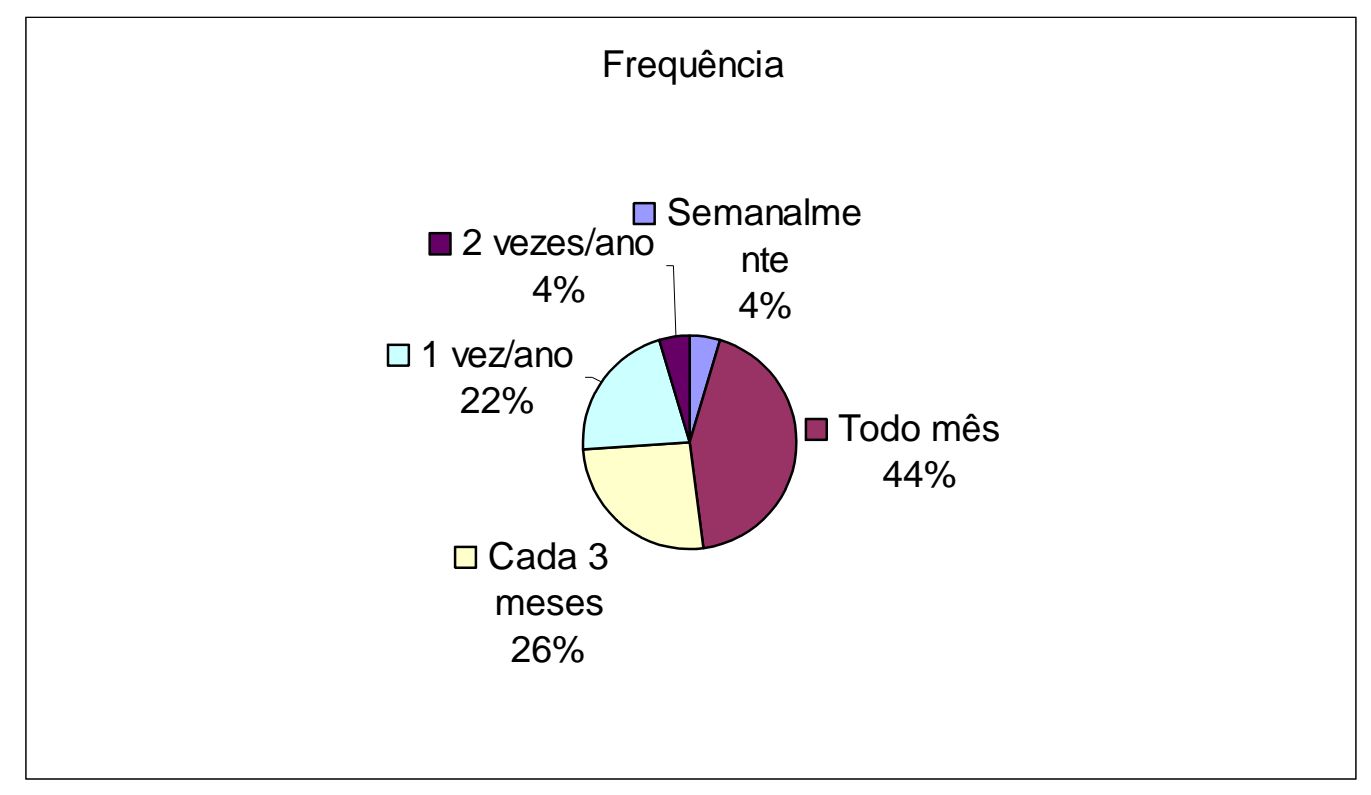

GRÁFICO 6 - Frequência em atividades de lazer nas escolas 
Entre os vinte e três entrevistados que afirmaram participar de atividades de lazer nas escolas, dez fazem-no semanalmente; seis, a cada três meses; cinco uma vez por ano; um, duas vezes ao ano e um vai semanalmente.

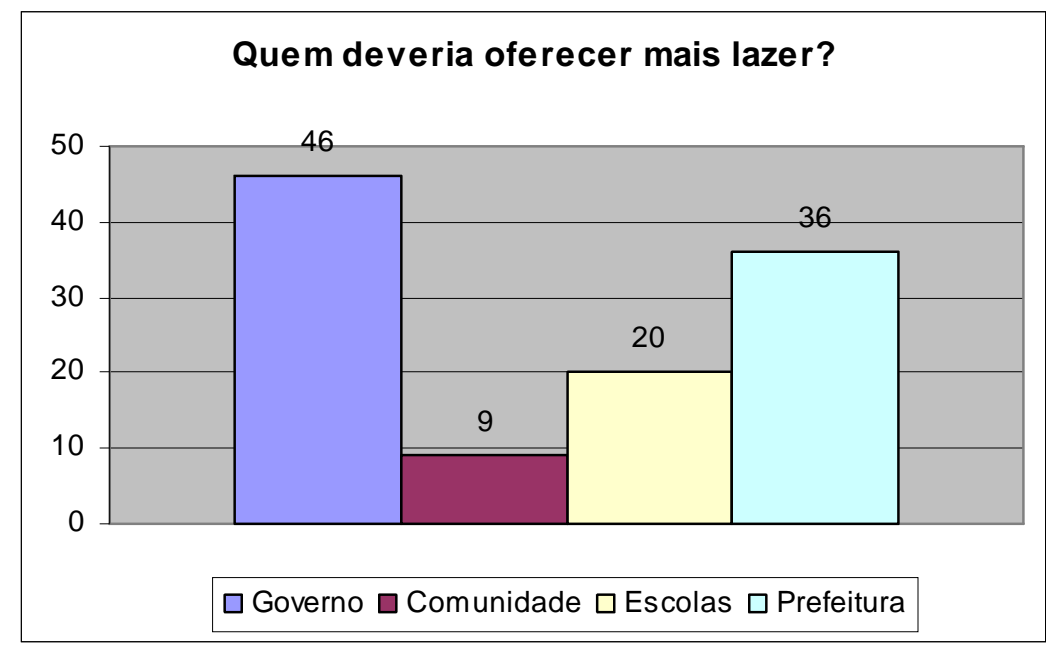

GRÁFICO 7 - Quem deveria oferecer mais lazer?

Para a maioria dos entrevistados, o Governo é quem deveria oferecer mais lazer, estando em segundo lugar a Prefeitura, em terceiro as escolas e por último, a própria comunidade. Como o Governo e a Prefeitura constituem ambos diferentes dimensões da esfera administrativa oficial, deduz-se que a responsabilidade é atribuída efetivamente ao Governo.

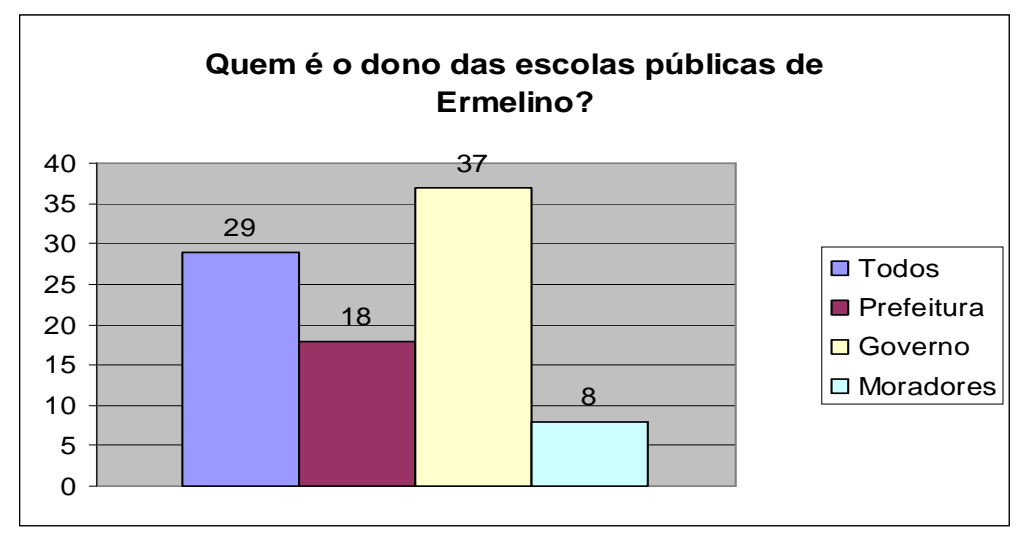

GRÁFICO 8 - Quem é o dono das escolas? 
Para esta questão, a maioria dos entrevistados apontou mais uma vez a Prefeitura e o Governo, como donos das escolas, estando em terceiro lugar a opção "Todos" e por último, os moradores.

Quanto à questão sobre se se sentiam donos das escolas, 58\% dos entrevistados afirmou que não e $42 \%$, que sim; perguntados também sobre se os moradores cuidavam das escolas, $75 \%$ das respostas foram que negativas, $24 \%$ positivas e uma pessoa não respondeu. Finalmente, `a pergunta sobre possibilidade de participação voluntária para manter ou ampliar as atividades de lazer, mais uma vez, 58\% respondeu que "não" e $42 \%$ que "sim".

O que se pode resumir a partir do exposto, contrapondo-se resultados da pesquisa com dados disponibilizados pela Prefeitura do Município de São Paulo é que o Distrito Municipal de Ermelino Matarazzo não está caracterizado por um nível socioeconômico muito baixo; que a população é jovem e o nível de escolaridade situa-se em torno de seis anos de estudo.

Além disso, a partir inclusive de pesquisas de campo, constatou-se que não há equipamentos públicos específicos para as atividades de lazer, com exceção do Parque Ecológico do Tietê e que as escolas oferecem algumas possibilidades dessas práticas, embora nem todos os entrevistados tenham reconhecido isso.

Por outro lado, eles não se sentem donos das escolas, não cuidam delas e acham também que ao Governo, incluindo-se a Prefeitura, caberia oferecer mais lazer para a população.

Por outro lado, ao se cruzar duas variáveis: "frequência ás atividades de lazer" e "sentir-se dono das escolas", constatou-se que entre vinte e três entrevistados que frequentam atividades de lazer nas escolas, sete sentem-se donos dela (escola), ou seja, trinta por cento (Vale observar, que por fatores não identificados, somente trinta e nove pessoas responderam à questão sobre frequência ou não `as atividades de lazer nas escolas).

Enquanto isso, entre dezesseis pessoas que não frequentam atividades de lazer nas escolas, quatorze não se sentem donos delas, ou seja, oitenta e sete por cento; por outro lado, 
somente duas pessoas desse conjunto (que não frequentam atividades de lazer nas escolas) isto é, doze por cento, sentem-se donos dessas mesmas escolas. Ou seja, a frequência às práticas de lazer nas escolas aumenta a possibilidade dos moradores sentirem-se donos dessas mesmas escolas e, portanto, responsáveis por elas.

Um outro dado importante que se pode depreender da pesquisa, diz respeito aos fatores que justificam a sensação de "não pertencimento" ou "não posse" sobre a escola; é não poder decidir sobre o que acontece nela, sendo comuns respostas como: "não mando"; "mando só na minha casa"; "porque não podemos participar com nossas opiniões" e "não decido nada", entre outras.

Essa constatação poderia ser aproveitada pelos responsáveis nas escolas públicas Federais, Municipais e Estaduais, mais especialmente nas estaduais de ensino médio, que sofrem com atos de vandalismo e de destruição do patrimônio, para que tomem iniciativas no sentido de chamar a população local à participação, de modo a tentar diminuir as ocorrências dessa natureza, fortalecendo-se por outro lado, o sentido do pertencimento, do compartilhamento numa comunidade

\section{Considerações finais}

O objetivo desta pesquisa foi contribuir para o esclarecimento de aspectos pertinentes à problemática do lazer no atual momento da sociedade urbano-industrial ou pós moderna, como querem alguns, e em especial em sociedades ou países em desenvolvimento como o Brasil, no qual se destaca a Grande Metrópole ou Região Metropolitana da Grande São Paulo.

Nesse contexto, a ênfase foi para as periferias de baixa renda dessa mesma Metrópole, e que no caso de São Paulo, como a Zona Leste e mais especificamente Ermelino Matarazzo, estão desprovidas de padrões desejáveis de urbanização, com sistemas de transporte sobrecarregados e que sofrem especialmente com a ausência de equipamentos públicos de lazer. 
Na verdade, parece que os únicos equipamentos públicos efetivamente presentes são as escolas e daí seu uso para práticas de lazer, que se viabilizou no Programa Escola da Família; esse Programa abre as escolas aos finais de semana oferecendo atividades de lazer desenvolvidas por voluntários e alunos universitários que prestam serviços em troca de bolsas oferecidas pelo Governo do Estado de São Paulo, em cursos superiores oferecidos por instituições conveniadas.

Para muitos, essa ação representaria uma instrumentalização de práticas de lazer com vistas à diminuição dos índices de violência, oferecendo-se alternativas para a numerosa população jovem e mais vulnerável do Distrito Municipal de Ermelino Matarazzo, numa perspectiva funcionalista, procurando também suprir carências mais estruturais com medidas de natureza quase paliativa.

De qualquer forma, apesar dessas possíveis restrições, foi pensada esta pesquisa que a partir de referenciais teóricos pertinentes à questão do lazer, educação e desenvolvimento, montou um instrumento de coleta de dados (em anexo) e que de início buscou definir o perfil dos entrevistados, que deveriam ter mais de dezoito anos, ser homem ou mulher e estudar/morar ou não na região de Ermelino Matarazzo.

A pesquisa foi aplicada durante o mês de maio, perfazendo-se um total de noventa questionários, além de outros dez que foram aplicados a educadores ou universitários que atuam nas escolas no desenvolvimento das atividades de lazer.

Os resultados apontam para um Bairro no qual a condição socioeconômica não é tão precária como se poderia supor inicialmente, estando a renda familiar mensal, de predominantemente assalariados e autônomos, em torno de $\mathrm{R} \$ 1.000,00$ (um mil reais); a escolaridade corresponde a seis anos de estudo e há forte presença de população jovem, entre de 18 e 24 anos. 
Para a maioria dos entrevistados, Ermelino não oferece possibilidades de práticas de lazer e aquelas oferecidas nas escolas são avaliadas positivamente; além disso, a maioria também não se sente dono das escolas do Bairro, registrando-se uma relação positiva entre os que frequentam as atividades de lazer aos finais de semana e que se sentem donos da escola.

Por outro lado, constatou-se também que parcela significativa deles gostaria de colaborar voluntariamente para a ampliação e manutenção das atividades de lazer e finalmente, que a maioria dos entrevistados não se sente dono da escola na medida em que não tem nenhum poder de decisão sobre ela.

Ou seja, este dado deveria ser considerado na orientação de políticas públicas em relação ao lazer nas escolas e em relação às escolas em geral, de chamada à participação dos moradores, atendendo-se prioritariamente as escolhas para as quais foram chamados a opinar, de forma a colaborar no sentido de pertencimento e de atuação comunitária, tão carente no perfil do povo brasileiro. E quem sabe, diminuir as ocorrências de vandalismo e de depredação do patrimônio público construído a partir dos impostos pagos por esses mesmos moradores.

Quanto aos educadores entrevistados, algumas observações se destacam: a de que a destruição da escola diminuiu, não tendo acontecido mais pichações e quebra de carteiras; que os jovens destroem porque querem, porque não lhe "dói no bolso", não têm que pagar pelos prejuízos e que o melhor resultado do Programa depende do envolvimento da direção da escola.

Há muito que fazer junto às comunidades carentes da periferia de baixa renda do Município de São Paulo; para muitos os problemas são estruturais e supõem encaminhamentos mais radicais. Para outros, parecem não existir caminhos, alternativas. Mas é preciso acreditar no grande poder transformador de pequenas ações, como as que resultam da soma de esforços que caracteriza uma comunidade e mesmo da capacidade que essa mesma comunidade tem de realizar sua autogestão coletiva. Nesse sentido, é preciso delegar, compartilhar, confiar na 
capacidade humana de escolher, de decidir, característica que nenhuma carência socioeconômica pode impedir de acontecer.

\section{REFERÊNCIAS}

ANDRADE, Manuel Correia de. Geografia Econômica. 12.ed. São Paulo: Atlas, 1998.

CAMARGO, Luiz Octávio de Lima. O que é lazer. São Paulo: Brasiliense, 1992.

DEÁK, Csaba. Acumulação entravada no Brasil e a crise dos anos 80. In:

SCHIFFER, Sueli (Org.) O processo de urbanização no Brasil. São Paulo: EDUSP, 1999.

DUMAZEDIER, Joffre. Lazer e cultura popular. São Paulo: Perspectiva, 2004.

FREITAG, Bárbara. Escola, estado e sociedade. São Paulo: Cortez e Moraes, 1979.

GADOTTI, Moacir. Concepção dialética da educação. 15.ed. São Paulo: Cortez, 2006.

HAESBAERT, Rogério. Região, diversidade territorial e globalização. Geographia. Revista de Pós-Graduação em Geografia do Departamento de Geografia da Universidade Federal Fluminense. Rio de Janeiro, 1999, v.1, n.1, p. 15-39.

IANNI, Octavio. A era do globalismo. Rio de Janeiro: Civilização Brasileira, 2001.

MARCELLINO, N. C. Lazer e educação. 3.ed. Campinas: Papirus, 2004.

Políticas Públicas de Lazer. São Paulo: Alínea, 2008.

PINTO, Leila Mirtes Santos de Magalhães, MARCELlinO, N. C. (Org.) Políticas públicas de lazer. São Paulo: Alínea, 2008.

\section{Endereço da Autora:}

Madalena Pedroso Aulicino

Escola de Artes, Ciências e Humanidades (EACH)

Universidade de São Paulo

Rua Arlindo Bettio, n. 1000

CEP 03828-000 - São Paulo - SP 